\title{
Thermoresponsive polymer membrane for the local delivery of drugs
}

\author{
Charlene C Ng BSc Phm ${ }^{1}$, Yu-Ling Cheng PhD ${ }^{1,2}$, Bradley A Saville PhD ${ }^{1,2}$
}

CC Ng, Y-L Cheng, BA Saville. Thermoresponsive polymer membrane for the local delivery of drugs. J Sex Reprod Med 2001;1(1):21-27.

OBJECTIVE: To develop a temperature-responsive polymer membrane that is permeable to drug only at temperatures above $42^{\circ} \mathrm{C}$. A triggerable implant that releases drug only when heated can be made by encapsulating a drug reservoir with such a thermoresponsive membrane. Such an implant can be applied in clinical situations in which it is desirable to release drug only on demand, such as erectile dysfunction. METHODS: A porous polyethylene (PE) membrane was modified by fillings its pores with either docosane or a docosane:eicosane mixture. The melting transition of the alkanes corresponds to a diffusional switch, thus, the alkane melting point corresponds to the membrane release trigger temperature. The onset of melting for each alkane and the alkane mixture was measured by differential scanning calorimetry. Using a diffusion cell, the permeability of propranolol hydrochloride (PRO) through the thermoresponsive membrane was measured.

RESULTS: PRO permeation through the docosane-absorbed PE membrane at $37^{\circ} \mathrm{C}$ and $45^{\circ} \mathrm{C}$ was reversible, and was reproducible after five cycles of temperature oscillation. From an aqueous solution reservoir, the ratio of PRO permeability through the docosane-absorbed PE membrane at $45^{\circ} \mathrm{C}$ versus $37^{\circ} \mathrm{C}$ was $378 \pm 65$. Similarly, the ratio of PRO permeability through the docosane:eicosane (90:10) PE membrane at $42.5^{\circ} \mathrm{C}$ and at $37^{\circ} \mathrm{C}$ was $235 \pm 56$.

CONCLUSIONS: The high on/ off permeability ratio achieved with PRO provides promise for the development of a thermoresponsive implant by using this membrane and a suitable drug. Local heating of the implant may be achieved by external power sources such as ultrasonic or microwave heaters.

\section{Membrane polymérique thermosensible pour l'administration locale de médicaments}

OBJECTIF : Mettre au point une membrane polymérique thermosensible, perméable aux médicaments seulement à des températures supérieures à $42^{\circ} \mathrm{C}$. On pourrait concevoir un implant dans lequel serait encapsulé un réservoir muni d'une membrane thermosensible, capable de libérer un médicament lorsqu'il serait chauffé. Ce type d'implant pourrait s'avérer utile dans les situations cliniques où la libération du médicament se ferait sur demande seulement, comme dans les cas de dysérection.

MÉTHODE : On a modifié une membrane de polyéthylène (PE) poreuse en appliquant du docosane ou un mélange de docosane et d'eicosane. Le point de fusion des alcanes correspond au point de diffusion; ainsi, le point de fusion des alcanes correspond à la température de libération de la membrane. Le début de la fusion de chaque alcane et du mélange d'alcane a été mesuré par calorimétrie à balayage différentiel. On a ensuite mesuré, à l'aide d'une cellule de diffusion, la perméabilité du chlorhydrate de propranolol $(\mathrm{CP})$ à travers la membrane thermosensible.

RÉSULTATS : Le passage du $\mathrm{CP}$ à travers la membrane de PE imprégnée de docosane s'est montré réversible à $37^{\circ} \mathrm{C}$ et à $45^{\circ} \mathrm{C}$ et reproductible après cinq cycles $\mathrm{d}^{\prime}$ oscillation de la température. Le rapport de perméabilité du $\mathrm{CP}$ à $45^{\circ} \mathrm{C}$ et à $37^{\circ} \mathrm{C}$ à partir d'un réservoir de solution aqueuse à travers la membrane de PE imprégnée de docosane était de $378 \pm 65$. Quant au rapport de perméabilité du $\mathrm{CP}$ à $42,5^{\circ} \mathrm{C}$ et à $37^{\circ} \mathrm{C}$ à travers la membrane de PE imprégnée de docosane et d'éicosane (90/10), il était de $235 \pm 56$

CONCLUSION : Le rapport élevé de perméabilité (début/fin) atteint par le $\mathrm{CP}$ s'avère prometteur pour la mise au point $\mathrm{d}^{\prime}$ un implant muni d'une membrane thermosensible et d'un médicament approprié. Le chauffage local de l'implant pourrait se faire par des sources externes d'énergie, par exemple des dispositifs aux ultrasons ou aux micro-ondes.

Key Words: Erectile dysfunction; Liquid crystal; Porous polymer membrane; Temperature-responsive drug delivery

\footnotetext{
${ }^{1}$ Faculty of Pharmacy, University of Toronto; ${ }^{2}$ Department of Chemical Engineering and Applied Chemistry, University of Toronto, Toronto, Ontario Correspondence and reprints: Dr BA Saville, Department of Chemical Engineering and Applied Chemistry, University of Toronto, 200 College Street, Toronto, Ontario M5S 3E5. Telephone 416-978-7745, fax 416-978-8605, e-mail saville@chem-eng.toronto.edu
} 
A fter years of responsive drug delivery research, many concepts to trigger the release of drugs on demand have been identified; however, few such delivery systems are in clinical use. It has been demonstrated that drugs can be delivered in response to physical changes such as temperature, $\mathrm{pH}$ and light (1). The need now is to integrate and test such responsive drug delivery concepts within the context of specific therapeutic applications. The long term objective of this research is to develop a triggerable, drugreleasing penile implant that exploits an existing thermoresponsive drug-release concept for the treatment of erectile dysfunction. When the proposed device is implanted in a patient, it could release the appropriate amount of drug to the cavernosal cavity only when triggered by external heating. With the proper choice of drug, such a thermoresponsive implant has the potential to provide on-demand therapy for erectile dysfunction and other diseases when local, intermittent delivery is desirable.

The drug-release trigger for a responsive implant should be tolerable physiologically. The core temperature of the human body can range from $37^{\circ} \mathrm{C}$ to $42^{\circ} \mathrm{C}$; because pain usually does not occur until skin temperature reaches $45^{\circ} \mathrm{C}$ to $50^{\circ} \mathrm{C}(2)$, heating to elevate the tissue temperature to between $42^{\circ} \mathrm{C}$ and $45^{\circ} \mathrm{C}$ can be used as a signal for responsive drug release. External power sources can be used to selectively heat implanted devices via radiative heating while minimizing the heating of surrounding tissue. For example, microwave heating has been used in transurethral hyperthermia treatment in which tumours are heated while the urethral epithelium is unaffected (3). Ultrasound can be used to focus power on a target site, such as the urinary bladder and kidney, and allow selective destruction of tissue at a particular depth (4). The same extracorporeal heating devices can be used to trigger drug release from the thermoresponsive implant, with minimal effect on surrounding tissue.

Porous substrates can be modified to produce membranes with variable and controllable permeability. Responsive materials can be either physically placed in the pores or covalently attached to the pore surfaces (Figure 1). The porous substrate acts as an inert and, usually, impermeable physical support, while the pore-filling, responsive materials, such as polymers (5), cross-linked hydrogels (6) and liquid crystals (7), respond to external stimuli to control drug diffusion. Temperature-responsive materials that have been widely investigated include hydrophilic polymers, which undergo solubility changes at characteristic lower critical solution temperatures (LCST), and liquid crystalline materials, which undergo melt transitions at characteristic temperatures. A widely studied hydrophilic polymer is poly(N-isopropylacrylamide) (pNIPAAm), which has an LCST in water of $32^{\circ} \mathrm{C}$ to $34^{\circ} \mathrm{C}(8)$. The difference between the permeability below and above the LCST for pNIPAAmgrafted porous membranes is usually small, particularly for low molecular weight solutes, most likely because membrane pore hydration does not change significantly between the collapsed and expanded states of grafted pNIPAAm $(9,10)$.

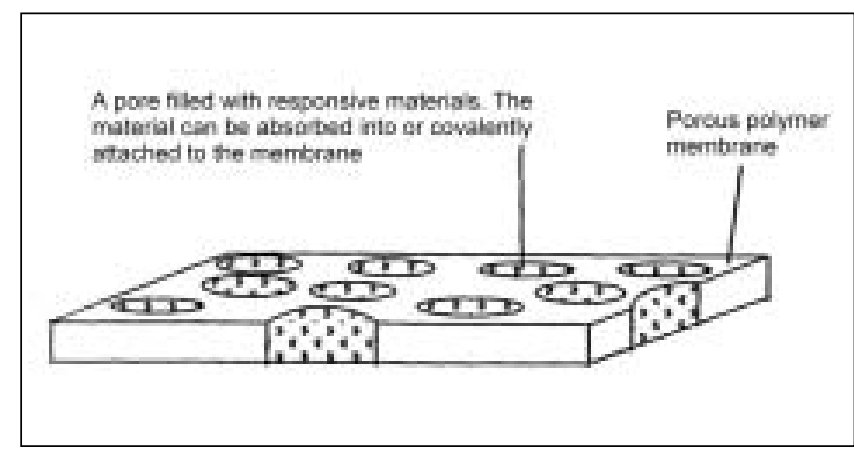

Figure 1) Microscopic view of the signal-responsive modified porous polymer membrane

Liquid crystal-absorbed membranes show greater differences in permeability below and above the melt transition temperatures of the liquid crystals. Nozawa et al $(7,11,12)$ embedded porous membranes with liquid crystals, such as mono-oxyethylene trimethylolpropane tristearate, and demonstrated sharp thermal responsiveness for the delivery of indomethacin and ketoprofen in vitro. In vivo transdermal application of this device showed, however, that skin offered significant mass transfer resistance and that prolonged heating was required to sustain elevated plasma levels.

Lin et al (13) demonstrated a similar concept by embedding cholesteryl oleyl carbonate in cellulose nitrate membranes and showed temperature-induced on/off switching permeation of salbutamol sulphate. Their particular design suffered, however, from the nonphysiological phase transition temperature of cholesteryl oleyl carbonate $\left(18^{\circ} \mathrm{C}\right)$ and a lack of reproducibility over four temperature cycles. Burillo et al (14) grafted acryloyl chloride onto polyethylene film to obtain films of liquid crystalline polymers. However, they did not perform any solute permeability studies on the film. Others prepared liquid crystalline membranes by solvent casting and demonstrated selective air separation at different temperatures $(15,16)$.

Ideally, the thermoresponsive membrane should be essentially impermeable at normal body temperature and at elevated temperatures that may prevail during common illnesses. We chose to fill porous membranes with lipophilic crystalline materials, such as alkanes, which would undergo a melting transition in the temperature range of $42^{\circ} \mathrm{C}$ to $44^{\circ} \mathrm{C}$. The upper and lower limits were selected by considering the heat-induced pain threshold of skin (2) and the typical temperature that can be reached during a fever $\left(41^{\circ} \mathrm{C}\right.$ to $42^{\circ} \mathrm{C}$ ) (17). Below the melting temperature, the alkane chains would be 'frozen' in an orderly crystalline structure, thus preventing the permeation of solutes. Above the melting temperature, the alkyl chains would be mobile and would be arranged in an amorphous liquid fashion that permits solute permeation. Due to their hydrophobic nature, the alkane molecules would remain confined to the pores of the substrate and would not be released into the surrounding tissue, even in a molten state. An appropriate mixture of docosane and eicosane was found to provide the desired melting tem- 
perature and, thus, was used as the pore-filling material. Propranolol hydrochloride (PRO) was used as a model drug for diffusion experiments to demonstrate the thermal responsiveness of the alkane-filled membranes.

\section{METHODS}

DL-PRO salt, n-docosane and n-eicosane were purchased from Sigma-Aldrich Canada (Canada). Porous polyethylene (PE) membranes were a gift from 3M (Canada) and were supplied as a flat sheet with $50 \mu \mathrm{m}$ thickness, $70 \%$ porosity and an average pore size of $0.2 \mu \mathrm{m}$. Deionized water that was collected from a Milli-Q water filtration system (Millipore, USA) was used. All of the other chemicals that were used were of reagent grade.

\section{PRO assay}

The concentration of PRO aqueous samples was determined by measuring ultraviolet absorbance at $290 \mathrm{~nm}$ with a spectrophotometer. The absorbance values were linearly related to PRO concentrations between 5 and $60 \mu \mathrm{g} / \mathrm{mL}$. Five data points were used to generate the standard curve with $\mathrm{R}^{2}=0.9988$, and there was little day-to-day variability.

\section{Melting point determination of the mixture of alkanes}

Two saturated straight chain alkanes, docosane and eicosane, have melting temperatures near the range of interest: $44.4^{\circ} \mathrm{C}$ and $36.8^{\circ} \mathrm{C}$, respectively. A mixture of these two components should form a highly compatible molecular solution with an intermediate melting temperature. Docosane and eicosane mixtures of varying mole fractions were melted and physically blended on a hot plate. The thermal transitions of the alkanes were also measured using a differential scanning calorimeter, DSC 2010 (TA Instruments, Canada), at a heating rate of $1^{\circ} \mathrm{C} / \mathrm{min}$. The extrapolated onset of the thermal transition peak was reported as the melting point.

\section{Alkane-absorbed polymer membrane preparation}

To prepare alkane-absorbed membranes, the desired alkane or alkane mixture was heated in an oven that was maintained at a temperature above the melting point of the alkane, then a preweighed PE membrane was soaked in the melted alkane for 30 to $60 \mathrm{~min}$ in the oven. After the removal of the membrane from the liquid alkane, the membrane was repeatedly washed in $60^{\circ} \mathrm{C}$ water bath and blotted dry with Kimwipes (Kimberly-Clark, Canada) until the weight of the membrane was constant. The weight of alkane absorbed on the polymer membrane was determined from the weight change of the polymer membrane before and after the alkane addition.

\section{Thermoresponsiveness}

Membrane thermoresponsiveness was characterized by measuring the change in PRO permeability across the membrane at different temperatures. The permeability of PRO through the unmodified PE membranes was compared with that through the alkane-absorbed PE membranes. Unmodified

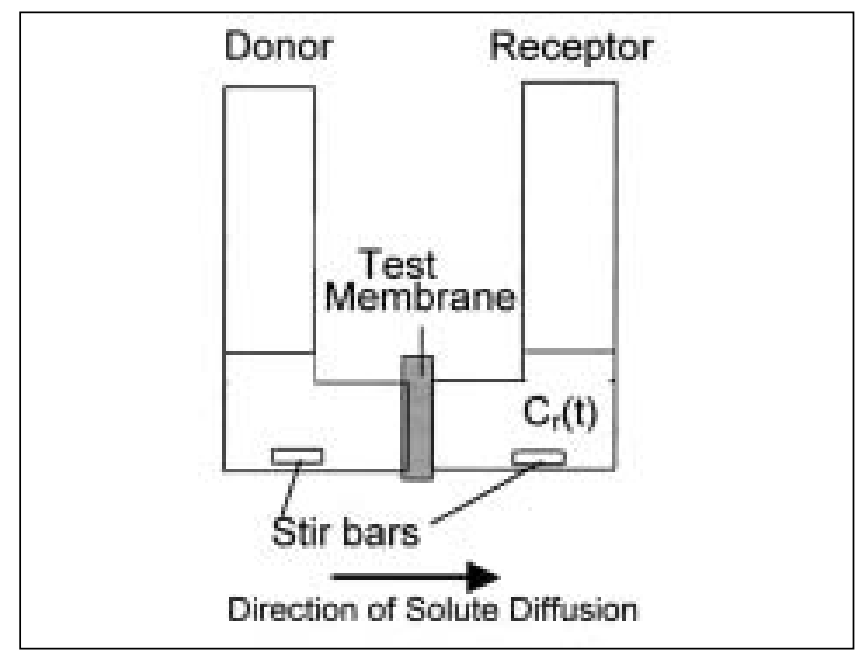

Figure 2) Diffusion cell for the determination of membrane permeability. The concentration of the solute in the receptor cell $\left(\mathrm{C}_{r}\right)$ was monitored over time

PE polymer membranes were first wetted with methanol, then left in $\mathrm{pH} 7.4$ buffer for at least $8 \mathrm{~h}$. The exchange of methanol with buffer was carried out so that the pores of unmodified membranes were filled with buffer.

To determine the solute's permeability, the test membrane was clamped in a diffusion cell, with a cross-sectional area for transport of $2.0 \mathrm{~cm}^{2}$ (Figure 2). The cell was then immersed in a $37^{\circ} \mathrm{C}, 42.5^{\circ} \mathrm{C}$ or $45^{\circ} \mathrm{C}$ water bath. The receptor compartment was filled with $7 \mathrm{~mL}$ of $\mathrm{pH} 7.4,0.15 \mathrm{M}$ phosphate buffer while the donor compartment was filled with an equal volume of 500 to $800 \mu \mathrm{g} / \mathrm{mL}$ PRO solution. The concentration of PRO remained constant throughout the permeation experiments, and the appearance of solute in the receptor cell was monitored over time by ultraviolet absorbance at $290 \mathrm{~nm}$. The permeability of PRO through the membrane was determined using the following equation derived from Fick's Law (18):

$$
\ln \left(C_{0}-2 C_{r}\right)=-\frac{2 P A t}{V}+\ln C_{o}
$$

$\mathrm{C}_{\mathrm{O}}$ is the initial drug concentration in the donor compartment with volume $(\mathrm{V})$. The receptor compartment has the same volume as the donor with drug concentration $\left(\mathrm{C}_{\mathrm{r}}\right)$ at time $\mathrm{t}$. $\mathrm{P}$ is the permeability of the solute through membrane area $\mathrm{A}$ and is a product of the diffusion and partition coefficients.

The permeability of PRO through three independent batches of alkane-absorbed PE membranes was recorded. In each case, permeability was measured over five cycles of temperature oscillations.

\section{RESULTS}

Characterization of alkane-absorbed membranes

PE porous membranes were modified with docosane. Using the density of docosane, the membrane porosity reported by the manufacturer and the measured thickness, the predicted 
TABLE 1

Melting points of various alkanes

\begin{tabular}{lcc}
\hline Alkane & Chemical formula & Melting point $\left({ }^{\circ} \mathbf{C}\right)$ \\
\hline Eicosane & $\mathrm{C}_{20} \mathrm{H}_{42}$ & 36.8 \\
Heneicosane & $\mathrm{C}_{21} \mathrm{H}_{44}$ & 40.5 \\
Octadecyl cyclohexane & $\mathrm{C}_{24} \mathrm{H}_{48}$ & 41.6 \\
Heneicosyl cyclopentane & $\mathrm{C}_{26} \mathrm{H}_{52}$ & 42.0 \\
Docosane & $\mathrm{C}_{22} \mathrm{H}_{46}$ & 44.4 \\
Tricosane & $\mathrm{C}_{23} \mathrm{H}_{48}$ & 47.6 \\
Tetracosane & $\mathrm{C}_{24} \mathrm{H}_{50}$ & 50.9 \\
\hline
\end{tabular}

Data from references 19 and 20

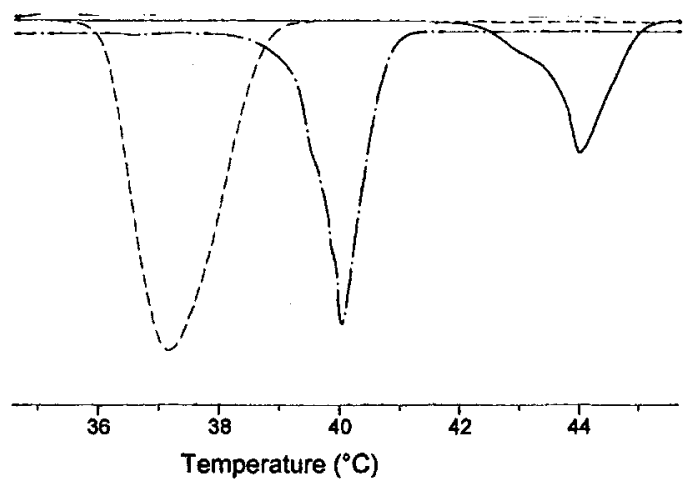

Figure 3) An overlay of differential scanning calorimeter traces of eicosane (---), docosane:eicosane (50:50) (-.-.-) and docosane (-)

weight gain of the membrane after alkane modification was estimated to be approximately $250 \%$. The actual weight gain was $227 \pm 19$ (mean $\pm \mathrm{SD}, \mathrm{n}=8$ ) and was in close agreement with the predicted value. The corresponding relation between the actual and predicted weight gain suggests that docosane filled only the pores and did not significantly plasticize the polymer.

The weight of the alkane-absorbed PE membrane became constant after about 10 cycles of washing and drying. The washing was intended to remove excess alkane from the surface of the membrane while leaving any alkane inside the pores untouched. Because the constant weight reached after 10 washing cycles was very close to the predicted weigh gain, this suggested that only surface docosane was removed by washing and/or blotting. Long chain alkanes are chemically similar to polyolefins and, thus, would be preferentially retained within the hydrophobic PE membrane; it is unlikely that they would be released into the surrounding aqueous medium, even in their molten state. This is consistent with the observation that the membrane mass remained constant after permeation experiments.

\section{Modification of the membrane transition temperature}

The desired release-trigger temperature for an implant is between $42^{\circ} \mathrm{C}$ and $44^{\circ} \mathrm{C}$, and can be controlled by the melting point of the pore-filling material. The melting tempera-

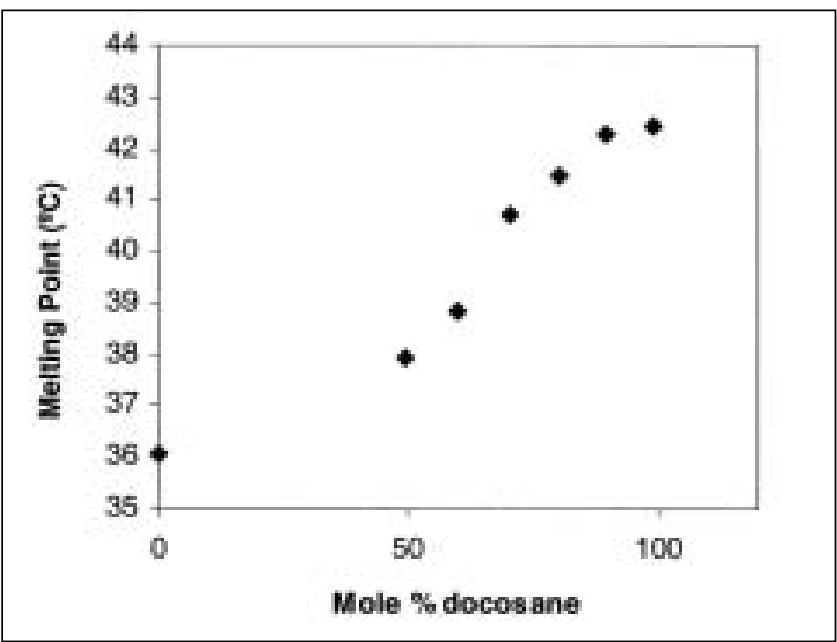

Figure 4) Average melting points $(n=2)$ of docosane:eicosane mixtures determined by differential scanning calorimeter at a heating rate of $1{ }^{\circ} \mathrm{C} / \mathrm{min}$. Variability was within the size of the symbol

tures of some alkanes that are near the range of interest are shown in Table $1(19,20)$. Two branched alkanes, octadecyl cyclohexane and heneicosyl cyclopentane, have melting temperatures in the desired range. Although they would be suitable pore-filling materials for this application, these branched alkanes were not available commercially. Two saturated alkanes, docosane and eicosane, have melting points that bracket the desired trigger temperature range. Because n-alkanes are structurally and chemically similar, they should form highly compatible molecular solutions with an intermediate melting point. To determine whether mixtures of docosane and eicosane formed molecular solutions, and to determine the thermal transition of the mixtures, calorimetry of the alkane mixtures was performed. Differential scanning calorimeter scans of docosane, eicosane and a 50 to 50 molar ratio mixture of the two alkanes are shown in Figure 3. Only a single and reversible melt transition was observed for the alkane mixture, indicating that the mixture does indeed form a single molecular solution.

Furthermore, as shown in Figure 4, the melting point of the docosane:eicosane mixture varied with composition. Consequently, the composition of such a mixture could be used to control the release (trigger) temperature. The 90:10 (mole \%) docosane:eicosane mixture had a melting temperature of $42^{\circ} \mathrm{C}$, which was within the range of the desired device-trigger temperatures. In initial experiments, docosane was used as the pore-filling material to demonstrate the concept of membrane thermoresponsiveness. In later experiments, the 90:10 docosane:eicosane mixture was used as the pore-filling material.

Thermoresponsive permeation of propranolol hydrochloride Porous PE membranes filled with either pure docosane or a 90:10 molar mixture of docosane:eicosane with melting points of $42.4^{\circ} \mathrm{C}$ and $42.1^{\circ} \mathrm{C}$, respectively, were used to characterize membrane thermoresponsiveness. Figure 5 shows 


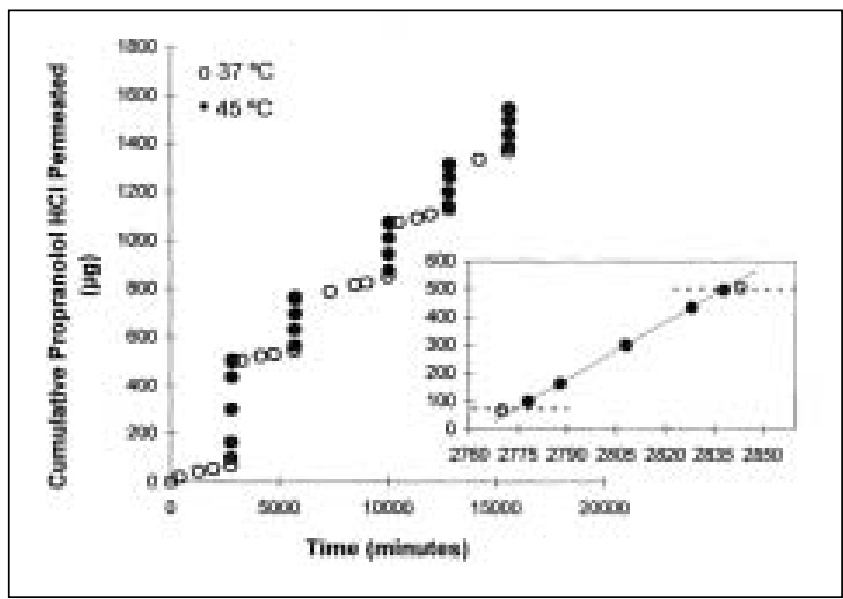

Figure 5) Cumulative propranolol hydrochloride permeated through a typical docosane-absorbed polyethylene membrane at $37^{\circ} \mathrm{C}$ and $45^{\circ} \mathrm{C}$. Inset: Expanded view of data between 2760 to $2850 \mathrm{~min}$

the dynamic permeation of PRO through a docosaneabsorbed PE membrane for five cycles of temperature oscillation between $37^{\circ} \mathrm{C}$ and $45^{\circ} \mathrm{C}$. The duration of each cycle was not constant in this experiment. The data showed reproducible and reversible permeation behaviour between the two temperatures. The inset graph in Figure 5 illustrates the membrane's rapid response to temperature changes. The slope of the cumulative release curves within each temperature range was proportional to the permeability of the membrane. Within $8 \mathrm{~min}$ of placing the diffusion cell in the higher temperature water bath (eg, at $2770 \mathrm{~min}$ ), there was a noticeable increase in membrane permeability. Similarly, within 5 min of lowering the membrane temperature (eg, at $2835 \mathrm{~min}$ ), no additional PRO was detected in the receptor compartment. Figure 5 shows that if the incubation time in the 'on state' is varied, the total amount of drug that permeates through the membrane in that cycle also varies accordingly. Thus, in a clinical device, the duration of heating is a parameter that the patient may use to adjust dosing.

Figure 6 shows that the on/off permeabilites and the steady state average permeability of the membranes in each temperature cycle are reproducible among the five cycles. Similar PRO permeation behaviour was observed using the eicosane to docosane-absorbed PE membrane with oscillating temperature cycles between $37^{\circ} \mathrm{C}$ and $42.5^{\circ} \mathrm{C}$.

The permeabilities of PRO through the alkane-absorbed membranes at different temperatures are summarized in Table 2. The trigger temperature of docosane-absorbed PE membrane was $45^{\circ} \mathrm{C}$, while that of the docosane:eicosane (90:10)-absorbed PE membrane was $42.5^{\circ} \mathrm{C}$. At the trigger temperature, the membrane is switched 'on', allowing the solute to diffuse through the membrane. At body temperature, however, the membrane is switched 'off', and minimal solute can diffuse through the membrane. The on/off ratio or $\mathrm{P}_{\text {on }} / \mathrm{P}_{\text {off }}$ is defined as the permeability of the solute at the on-state of the membrane divided by the permeability at the off-state. The mean on/ off ratios of the docosane-

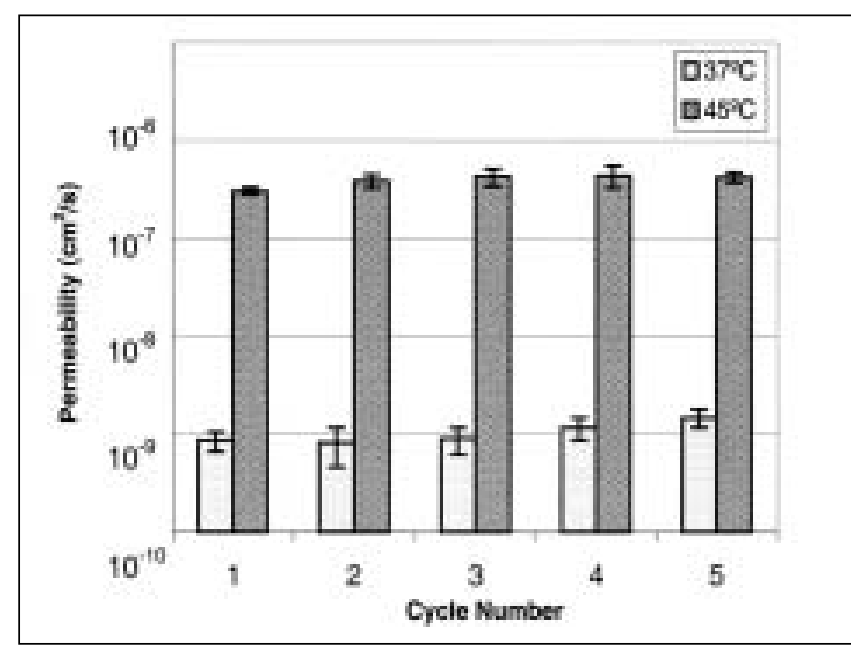

Figure 6) Permeabilities of propranolol hydrochloride through the docosane-absorbed polyethylene membranes for five cycles of temperature oscillation between $37^{\circ} \mathrm{C}$ and $45^{\circ} \mathrm{C}(n=3$; error bars indicate $95 \% \mathrm{CI})$

TABLE 2

Summary of the permeabilities of propranolol hydrochloride through alkane-absorbed polyethylene (PE) membranes

\begin{tabular}{lcc}
\hline & $\begin{array}{c}\text { Docosane-absorbed } \\
\text { absorbed PE membrane }\end{array}$ & $\begin{array}{c}\text { Docosane:eicosane } \\
(\mathbf{9 0 : 1 0}) \text {-PE membrane }\end{array}$ \\
\hline $\mathrm{P}_{\text {off }}\left(\mathrm{cm}^{2} / \mathrm{s}\right)$ & $1.04( \pm 0.16) \times 10^{-9}$ & $7.87( \pm 0.66) \times 10^{-10}$ \\
$\mathrm{P}_{\text {on }}\left(\mathrm{cm}^{2} / \mathrm{s}\right)$ & $3.93( \pm 0.30) \times 10^{-7}$ & $1.85( \pm 0.41) \times 10^{-7}$ \\
$\mathrm{P}_{\text {on }} / \mathrm{P}_{\text {off }}$ & $378( \pm 65)$ & $235( \pm 56)$ \\
\hline
\end{tabular}

Data are mean $\pm S E$

absorbed membranes and docosane:eicosane-absorbed membranes were $378 \pm 65$ and $235 \pm 56$ (mean \pm SE of the mean), respectively. The large on/off ratio indicates that the permeability of the membranes increases drastically at the 'on' temperature. Furthermore, the on and off permeabilities are reproducible over five cycles of temperature oscillation.

There is a large difference between PRO permeability through the alkane-absorbed membrane in the off state and that through the unmodified membrane at $37^{\circ} \mathrm{C}$. The permeability of PRO through the unmodified membrane was 1.59 $( \pm 0.37) \times 10^{-6}$ at $37^{\circ} \mathrm{C}$, which is about 1500 to 2000 times greater than the permeability of PRO through the alkanemodified membrane at the same temperature (Table 2). The presence of the solid alkane in the pores, thus, dramatically reduces drug permeability, ensuring that very little drug will be released in the off state. Increasing the temperature to $42.5^{\circ} \mathrm{C}$ or $45^{\circ} \mathrm{C}$ did not measurably change PRO permeability through the unmodified membrane, but PRO permeability through the modified membrane increased by a factor of about 200 to 400 (Table 2). Nonetheless, PRO permeability through the unmodified membrane was still about six to 10 times greater than that through the alkane-modified membrane. This observation indicates that the rate of PRO 
diffusion through a liquefied alkane is similar to that of PRO diffusion through water-filled channels.

To trigger a change in membrane permeability, the diffusion cell apparatus was heated by immersion in a higher temperature bath, ie, by conduction. The permeation experiments (eg, Figure 5) showed that drug release was triggered within $8 \mathrm{~min}$ of conductive heating. When designing a radiative heater for clinical use, care should be taken to ensure that the heating of the implant is fast enough so that drug release can occur within an acceptable time frame.

Cooling of the membrane was achieved by removing the setup from the heat source and placing it into a $37^{\circ} \mathrm{C}$ water bath, where conductive cooling occurred. This kind of cooling mimics the clinical scenario in which the implant is cooled conductively and convectively by the circulating blood and the surrounding tissues. When this cavernosal implant is used for erectile dysfunction, for instance, the onset of the pharmacological effect (ie, vasodilation) would act as negative feedback to lower the temperature of the implant and, thus, eventually, shut off the device and prevent further drug release. It can be inferred from the available data that the thermoresponsive implant would stop releasing drug within 5 min of its removal from the heat source.

\section{Other considerations in the design of the thermoresponsive drug implant}

Subsequent studies will need to consider the stability of the drug within the pore-filling material, the partition coefficient and the relative solubility of the drug in the pore-filling material and the internal drug reservoir, and the biocompatibility of the device. Drug stability is critical for long term implants, while drug solubility and partitioning dictate the drug loading and ease of transfer of the drug between the various regions of the implant (reservoir, pores) and the surrounding tissues. Practical considerations, such as the methods of implant insertion and retrieval, also need to be determined. The significance of such considerations are highly dependent on the drug, the location of the implant and the clinical application that is under consideration.

\section{CONCLUSIONS}

A thermally responsive drug delivery device was developed by filling the pores of a PE membrane with an appropriate long chain alkane. The trigger temperature for the membrane corresponds to the melting point of the alkane; the drug is essentially impermeable when the alkane is solid (below the trigger temperature), but the permeability increases by several orders of magnitude when the alkane is liquid (ie, above the trigger temperature). The choice of an alkane (or composition of an alkane mixture) allows the trigger temperature to be customized.

The membrane permeability changed rapidly (within less than $5 \mathrm{~min}$ ) in response to changes in temperature, and the permeability in the on and off states was maintained through several heating and cooling (on/off) cycles. Furthermore, the amount of drug released during the 'on' state could be controlled by varying the duration of heating; this feature is valuable in situations in which some measure of patient control over the dose is desired.

The current device design meets several of the clinical requirements of a subdermal implant, including those for the local delivery of drugs into the cavernosal cavity. The implant can be activated using, for example, deep heating ultrasonic devices that use single or multiple acoustic beams to focus the heating to the target site (4). This technology could be adapted to develop a heater that is suitable for the responsive drug delivery system described above. These concepts could, conceivably, be adapted and applied to any clinical situation in which local, intermittent delivery is required, encompassing a range of drugs and the treatment of many diseases.

\section{REFERENCES}

1. Ulbricht M. Photograft-polymer-modified microporous membranes with environment-sensitive permeabilities. Reactive Funct Polymers 1996;31:165-77.

2. Lawton B. Heat dose to produce skin burns in humans. In: Ebadian MA, Oosthuizen PH, eds. Fundamentals of Biomedical Heat Transfer. New York: The American Society of Mechanical Engineers, 1994;295:31-45.

3. de La Rosette JJ, D'Ancona FC, Debruyne FM. Current states of thermotherapy of the prostate. J Urol 1997;157:430-8.

4. ter Haar GR. Focused ultrasound surgery. In: Duck FA, Baker AC, Starritt HC, eds. Ultrasound in Medicine. Bristol: Institute of Physics Publishing, 1998:177-87.

5. Hautojarvi J, Kontturi K, Nasman JH, Svarfvar BL, Viinikka P, Vuoristo M. Characterization of graft-modified porous polymer membranes. Ind Eng Chem Res 1996;35:450-7.

6. Kapur V, Charkoudian J, Anderson JL. Transport of proteins through gel-filled porous membranes. J Membr Sci 1997;131:143-53.

7. Nozawa I, Suzuki Y, Sato S, Sugibayashi S, Morimot Y. Preparation of thermo-responsive polymer membranes. I. J Biomed Mater Res 1991;25:243-54.

8. Schild HG, Tirrell DA. Microcalorimetric detection of lower critical solution temperatures in aqueous polymer solutions. J Phys Chem 1990;94:4352-6.

9. Peng T, Cheng YL. Temperature-responsive permeability of porous PNIPAAm-g-PE membranes. J Appl Polym Sci 1998;70:2133-42.

10. Akerman S, Viinikka P, Svarfvar B, et al. Drug permeation through a tempeature-sensitive poly ( $N$-isopropylacrylamide) grafted poly (vinylidene fluoride) membrane. Int J Pharm 1998;164:29-36.

11. Nozawa I, Suzuki Y, Sato S, Sugibayashi K, Morimoto Y. Preparation of thermo-responsive membranes. II. J Biomed Mater Res 1991;25:577-88.

12. Nozawa I, Suzuki Y, Sato S, Sugibayashi K, Morimoto Y. Application of a thermo-responsive membrane to the transdermal delivery of non-steroid anti-inflammatory drugs and antipyretic drugs. J Control Release 1991;15:29-37.

13. Lin SY, Chen KS, Lin Y. pH of preparations affecting the on-off drug penetration behavior through the thermo-responsive liquid crystal-embedded membrane. J Control Release 1998;55:13-20.

14. Burillo G, Mendoza R, Fomine S, Ogawa T. Grafting of side chain liquid crystal monomers onto polyethylene film. Polym Bull 1997;39:489-94.

15. Temperature dependence and stability of oxygen enrichment 
through liquid crystalline triheptyl cellulose-containing membranes cast from three solvents. J Membr Sci 1996; 116:143-8.

16. Li X, Huang M, Hu L, Lin G, Yang P. Cellulose derivative and liquid crystal blend membranes for oxygen enrichment. Eur Polym J 1999;35:157-66.

17. Mackowiak PA, Boulant JA. Fever's upper limit. In: Mackowiak PA, ed. Fever: Basic Mechanisms and Management, 2nd edn. Philadelphia: Lippincott-Raven Publishers, 1997:147-63.

18. Martin A. Physical Pharmacy, 4th edn. Philadelphia: Lea Febiger, 1993:325.

19. Rappoport Z, ed. CRC Handbook of Tables for Organic Compound Identification, 3rd edn. Cleveland: The Chemical Rubber Co, 1987:8.

20. Lid DR, ed. CRC Handbook of Chemistry and Physics, 79th edn. Cleveland: CRC Press, 1998:3-134.

\begin{abstract}
A note from the Editor-in-chief
Before the introduction of oral erectogenic agents, a majority of patients who chose intervention were using intracorporal injection of vasoactive substances. A subdermal or penile reservoir of such a substance activated by an external device could be used to provide a more convenient, painless solution to patients who still require local therapy and do not respond to oral agents.
\end{abstract}

